\title{
English for Science and Technology: A Project Based Approach
}

\author{
Yiqun Yin \\ Department of Foreign Languages \\ Dalian Institute of Science and Technology \\ Dalian, China \\ yinyiqun666@163.com
}

\begin{abstract}
This paper deals with the importance of communicative skills and the learner-centered environment to the engineering students. Learner-initiated teaching approach satisfies students' needs. English language skills are essential for the engineering students to meet the requirements and needs of technical development in academy, employability and research. Under the circumstance, students have to attain both the subject knowledge and the scientific language to communicate. Courses that aim to meet such needs are categorized as English for science and technology (EST). But traditional EST program leads to engineering students' lack of language proficiency. According to questionnaires, interviews and class observations, the survey result finds that requirements of EST courses overlap the study skills of EAP courses, and EAP programs with a learner-centered PBL approach will be the best choice for engineering students. Besides, the result shows that EST teachers should acquire specialized competencies and get trained.
\end{abstract}

Keywords-Students' Need; Communicative Skills; EST; EAP; $P B L$

\section{INTRODUCTION}

Nowadays, the large proportion of the world's population uses English as a first or alternative language, and a large number of British Commonwealth members still retain English as their official languages. Approximately more than $80 \%$ of all scientific and technical information accessible to people worldwide is primarily published in English. Actually, the scope and scale of usage of English domains in some fields, and its influence continues to expand. From the beginning, America's world economic dominance expands the use of English into other fields; consequently, English, the international language, develops from tourism to business management, as well English for science and technology. Therefore, English has recognized as a major means of communication in the field of science and technology.

With the development of science and technology, the increasing number of students selects to study science in colleges or universities, and China also welcomes young people to acquire scientific knowledge to help the nation to modernize. Under the circumstance, students have to attain both the subject knowledge and the scientific language to communicate. Courses that aim to meet such needs are categorized as English for science and technology (EST), however, the course mainly focuses on linguistic aspects and few practical activities are organized, which contributes to

One of the research results of "Research on Cultivation Model for EST Talents from the Perspective of EAP Theory" (Project No: L16CYY007); which is supported by a grant from Liaoning Planning Foundation of Philosophy and Social Science in 2016. students' lack of English language proficiency. Over time, students have difficulties in reading and writing in English as well as communicating with others at lectures, seminars and international conferences. Given the need for academy, employment and scientific research, it is necessary for institutions to train their students with their English proficiency at tertiary education. English for academic purposes (EAP) program is introduced in this study. EAP course just covers the requirements of students, who need to read textbooks, give conference presentations and write essays In addition, the study adopts Project-based Learning (PBL) as an approach to guide the operation of EAP programs. PBL is a model that organizes learning around projects and focuses on questions or problems that drive students to encounter the central concepts and principles of a discipline.

In a word, the study tries to build up a teaching model that is based on EAP programs under the guidance of PBL. So the objectives of the study are listed as following:

To encourage the engineering students to involve actively in their own learning processes

To enhance their English literacy

To strengthen their speaking ability

To stimulate their interest and cultivate their critical thinking

To form their team spirit by doing group work

\section{LITERATURE REVIEW}

\section{Definition of EAP}

EAP has been defined as the "teaching of English with the specific aim of helping learners to study, conduct research or teach in that language" [1], with instruction based on the demands of academic disciplines [2].

The roots of EAP lie within the field of English for Specific Purposes (ESP), which focuses on teaching English for specific rather than general purposes [3]. EAP is one of the strands of ESP along with English for Vocational/Occupational Purposes (EVP/EOP) [4].

According to Blue, he categorizes EAP into English for general academic purposes (EGAP) and English for specific academic purposes (ESAP) [4], the former is concerned with general academic language and focuses on study skills; the 
latter examines the language features of particular academic disciplines or subjects [5].

As for needs analysis of EAP courses, that is, study skill courses. Jordan analyzes those skills respectively, including listening and note-taking, seminars and discussions, reading skills, academic writing, and reference skills [6]. It seems that study skills of EAP overlap greatly with that of EST, and two parts often share the same students, however, it is clear that EAP will be the best choice for engineering students. EST program constitutes the traditional teaching model in accordance with (English for General Purposes) EGP, which leads to engineering students' lack of language proficiency. As Weiss and Newman suggest writing is often challenging to scientists as there is insufficient training at universities [7]. Given the fierce competition for jobs and publications in the science sector, there is indeed a pressing need for universities to train their students academically before graduation. In response to the surging need of science communication training among engineering students, EAP courses are being offered.

\section{PROJECT-BASED LEARNING APPROACH}

According to the definitions found in PBL handbooks for teachers, projects are complex tasks, based on challenging questions or problems, that involve students in design, problem-solving, decision making, or investigative activities; give students the opportunity to work relatively autonomously over extended periods of time; and culminate in realistic products or presentations [8].

Project-based learning is an instructional method centered on learners. Students find a problem and are instructed through research under the supervision of teacher. Once the project is determined, students will plan, implement and evaluate projects, which simulate the real world beyond the classroom. Not only does project-based learning improve the quality of learning, but students' cognitive ability by virtue of student's engagement in the project. When teachers implement Project-based learning, students can be highly motivated, feel actively involved in their own learning. Project-based learning makes students involved in the learning procedures. This participation will be beneficial to students in two aspects. On the one hand, students can take control of their own learning procedures like decision-makings, plans and implementation and so on; on the other hand, students can interact with each other to get benefit maximization.

\section{METHODS}

In this study, the researchers utilize needs analysis to investigate students, teachers, and the EST course. Thereafter, there are some suggestions offered, relating to course design and teaching method. Emerging from these surveys is the view that EAP will be the suitable course with the Project-based learning approach.

Firstly, needs analysis figures out what is the students' real, current need and finds out students' weakness in English learning; and then, the researcher summarizes EST teachers' reflection on their teaching; finally, observes the EST class to know teachers' instruction and students' learning in the given situations. Both qualitative and quantitative approaches are applied to collect the research data, and the research findings are discussed on the analysis of data from the questionnaires, interviews and class observation. The questionnaire data were gathered from 332 participants (300 students majored in mechanics from department of Mechanical Engineering who are taking the EST course, 32 teachers of EST from English department) belonged to Dalian Institute of Science and Technology.

\section{FINDINGS}

\section{A. Needs Analysis Questionnaire to Students}

The questionnaire reflects that the students of engineering have realized the importance of EST:

The students considered that the skills that they need should be listed in such an order: speaking, reading, writing and listening.

Grammatical patterns of reading and writing in science field should be familiarized.

The memory of technical vocabulary should be intensified.

EST teachers not only need the linguistic abilities more than that of EGP teachers, but also acquire the expertise relating to the subject.

EST teachers should be tutors instead of dominators in the classroom; they should adopt the efficient teaching methods to design the teaching activities, and motivate students to participate in class activities.

\section{B. Teaching Reflection Questionnaire to Teachers}

95\% of EST teachers suggest that they should receive the specific training of English specialized knowledge and English language skills, such as:

The general teaching competences of the EST teachers includes teaching specialist academic subjects, capacity to design course, employing the project-based learning approach, ability to use language laboratory equipment.

Subject-content competence:

1) Speaking skills: oral presentation skills, interviews, seminars and discussions, etc.

2) Reading skills: definitions, generalizations, explanations examples, predictions, confirming logical relation, and distinguishing fact from opinion, etc.

3) Writing skills: audience awareness, logical organization, paragraph development, comparison and contrast, problem and solution, etc.

4) Listening skills: listening and understanding, notetaking, listening for key words and expressions, extracting relevant details, recognizing topics and main idea, etc.

5) Special grammatical usage: the usage of passive voice, tense, mood, etc. in scientific and technical communication. 
6) Vocabulary acquisition: vocabulary size and vocabulary depth, the use of terminology, etc.

\section{EST Class Observation}

In class observation, some students expressed the negative feelings in the class participation, as one student said that writing and reading part were not helpful because she felt that they repeated the lessons that she had learned in high school. According to the observation, the teachers lack the ability to do well in the EST courses, firstly, teachers play a dominate role in the class activities, and ignore the involvement of students. And then, EST teaching is confined to limited English environment. Sometimes teachers speak Chinese instead of English in class and say they are insufficient to use English as the teaching language, so this may be a barrier because it reduces opportunities for students to practice their communicative skills. Last but not least, teaching contents are lack of difficulty of EST. Teachers are used to teaching in a traditional way, they teach words, sentence structures and English-Chinese translation in class, students feel EST is not challenging. All in all, the teaching model is monotonous; there are a series of issues associated with objectives, content, organization, implementation and evaluation. Therefore, it is vital to reform the recent EST course, in the following part, the researcher will propose the feasible strategies.

\section{IMPLICATIONS FOR EST COURSES}

Students, who take EST courses, have the objective of enhancing their language proficiency, as is known to all, language proficiency, indeed is important, which depends on the students' English level to some degree. According to Needs Analysis Questionnaire to Students, the course design and implementation should meet the students' requirements and employability. The present EST courses do exist some problems that need to be solved urgently; as a result, many experts recommend that students should be offered a new teaching model, such as EAP courses, particularly attaching its importance to the combination of linguistic features and subject-contented context.

Given Teaching Reflection Questionnaire to Teachers, EST teachers should be equipped with general English skills and subject-content competences. EST teachers' knowledge consists of three parts, namely, English language knowledge, specialized subject knowledge and pedagogy knowledge. English language knowledge and specialized subject knowledge is the resource storehouse for imparting knowledge, and pedagogy education is the catalyst to ensure the smooth communication between teachers and students, and promote the effective construction of students' knowledge. Professional knowledge is difficult for teachers because it is not likely to be acquired or mastered by Self-Study in a campus or library, and it often requires exchanging experience with experts in the field. As for the needs of curricula design, the school can organize the relevant training activities within the school, and the knowledge and skills acquired by the trained teachers can be applied in class. In addition, by means of constant selfevaluation and self-reflection, teachers improve their language ability and self-development. It can be seen that teaching reflection is the core of teachers' self professional development.

Having analyzed EST Class Observation, the researchers found that the teacher-centered method does not work well; however, the PBL approach turn its instruction from teachercentered to student-initiated, leading to emphasis on students' cognition and acquisition. PBL approach is an effective method for teaching students complex processes and procedures such as planning, communicating, problem solving, and decision making, more important, there is some evidence that PBL has the value for enhancing the quality of students' learning in EST. The researcher concludes that EAP course model with PBL approach seems to be better than other models of instruction and teaching methods.

\section{A. Curriculum Development in EAP}

EAP is concerned with researching and teaching the English communicative skills needed by those who use the language to perform academic tasks. The field has developed greatly, driven by the global growth in the use of English for employment, as well as academic research. EAP courses are suggested for EST teachers to complete the class activities such as writing, reading, note-taking, listening to lectures, and participating in seminars and discussions, grammar and lexicon of technical scientific terms.

\section{B. PBL: A Learner-centred Approach}

PBL approach plays a significant role in improving learners' communicative skills. A learner-centred approach promotes learning by means of techniques involving learners in groups. It motivates students to learn, fostering problemsolving, and developing cooperative working skills. The EST teachers should adopt the PBL approach to let the learners acquire rich knowledge of the linguistic, functional, cultural, interactive, grammatical, semantic and lexical aspects to acquire communicative competence in English.

\section{Pedagogical Suggestions}

1) Speaking skills: there are general characteristics that teachers should pay attention to when they design the teaching activities relating to speaking.

a) Class size: make students aware of the features of different class sizes.

b) Class participation: build their skills and confidence in classroom interactions.

c) Work with classmates: build students' abilities to work cooperatively.

d) Oral presentations: train students to make presentations of different types.

e) Lecture comprehension: make students familiarize different presentation styles and note taking.

f) Interacting with teachers: help students feel more comfortable and develop their confidence

2) Reading skills: it is impossible in practice to separate reading from other skill like writing. 
a) Increase the input of English: promoting the reading ability of English is obviously closely related to the reading ability of EAP.

b) The input of academic English vocabulary: lexical knowledge is the key to succeed in reading for second language acquisition; it is more conducive to enhance EST reading ability than other kinds of linguistic knowledge (including syntax).

c) Schema reading model: while top-down reading pattern emphasizes the importance of meaning construction in the process of understanding, such as readers' participation, individual experience, and existing expertise.

d) Output-oriented reading facilitation: language input is critical to language acquisition, and comprehensible language output also contributes to language acquisition.

3) Writing skills: students' handling of writing assignments is largely based on previous writing experiences; it would seem useful to design writing courses that give students a variety of writing experiences.

a) Foster students' flexible attitude toward writing assignments: training them to analyze a variety of writing assignments and encouraging them to feel comfortable in questioning their teachers about them.

b) Address students' ongoing need for efficiency in language processing: this need is not addressed by isolated work with grammar and vocabulary but rather that speed of language processing only develops through extensive and repeated language processing in the process of accomplishing writing goals.

c) Consider the intellectual challenge posed by the assignments made in the writing course: The ability to engage intellectually demanding tasks well in language acquisition.

d) Given the importance of task management strategies: it would seem imperative to link reading to writing by helping students locate, read, evaluate and manipulate information from outside sources.

4) Listening skills: the high-ability listeners use six cognitive strategies. Of these, four are top-down: inference, elaboration, prediction and contextualization. All these strategies require the listener to make use of their prior knowledge.

a) Inference: listeners fill in missing information, for instance, meanings of unfamiliar words and parts of a text that they cannot hear clearly.

b) Elaboration: elaborating inferences relate new information to existing knowledge to produce a more complete interpretation.

c) Prediction: enables listeners to anticipate the next part of a text, such as a word, a phrase or an idea.

d) Contextualization: the attempts to relate new information to a wider context or situation in order to produce an acceptable general interpretation of it. e) Fixation: pay close attention to one small part of the spoken text in order to understand it.

f) Reconstruction: this involves using words from the text and sometimes background knowledge to construct the meaning of the original input.

\section{5) Grammatical competence}

Grammar should be taught for communication in context and has a close relationship with language skills. The EST teachers are suggested to offer meaningful input through contextualization and provide an opportunity to utilize grammar, and connect grammar instruction with real life situations. Grammar teaching should be treated in the same way as the teaching of four basic language skills which involves smooth and organized transitions.

6) Lexical competence: nowadays it is widely accepted that vocabulary is the difficult point for students, so vocabulary teaching should be added in the EST course. In the fields of Science and Technology, there are their own specialized terms and phrases. In fact, learners would have to come to the technical text with a larger vocabulary; there is value in the EST teachers paying attention to the high frequency technical vocabulary that occurs in some form in other disciplines.

\section{CONCLUSION}

In conclusion, based on the needs analysis to the students, teaching reflection to teachers and EST class observation, the researcher, has raised the critical and obvious issues that confront teachers, and learners and researchers of EST in present days; EAP courses offer the possibility of making even greater contributions to EST teaching, and PBL provides individual learning atmosphere to the students in the learning process. The findings of the study provide useful and pragmatic information to enhance students' communicative skills and improve the competences of the English teachers so that the students reap the benefits in accomplishing their language needs.

\section{ACKNOWLEDGMENT}

The paper is supported by a grant from Liaoning Planning Foundation of Philosophy and Social Science (No.L16CYY007), the author would like to thank the continuous support from Liaoning Planning Office of Philosophy and Social Science. Special acknowledgement goes to China University of Petroleum and Qingdao University for organizing the 2018 2nd International Conference on Management, Education and Social Science, which this paper was presented. 


\section{REFERENCES}

[1] J. Flowerdew and M. Peacock, Issues in EAP: A preliminary perspective. In J. Flowerdew \& M. Peacock, (Eds.), Research perspectives on English for academic purposes, Cambridge: Cambridge University Press, 2001, pp. 8-24.

[2] K. Hyland and L. Hamp-Lyons, "EAP: Issues and directions," Journal for Academic Purposes, vol. 1, pp.1-12, 2002.

[3] K. Hyland, English for academic purposes: An advanced resource book. London: Routledge, 2006.

[4] G. M. Blue, Individual academic writing tuition. In P. C. Robinson (Ed.), Academic writing: Process and product (ELT Documents 129, pp. 95-99). London: Modern English Publications, 1988. B. Coffey, "ESPEnglish for Specific Purposes,” Language Teaching, vol. 17, pp. 2-16, 1984.

[5] R. R. Jordan, "English for Academic Purposes (EAP)," Language Teaching, vol. 22, pp.150-164, 1989.

[6] M. Weiss and A. M. Newman, "A guide to writing articles in energy science,” Applied Energy, vol. 88, pp. 3941-3948, 2011.

[7] B. F. Jones, C.M. Rasmussen and M. C. Moffitt, Real-life problem solving: A collaborative approach to interdisciplinary learning. Washington, D.C: American Psychological Association, 1997. 